\title{
Prevalence of exercise and non-exercise physical activity in Chinese adolescents
}

\author{
Kwok-Kei Mak, Sai-Yin Ho ${ }^{1 *}$, Wing-Sze Lo ${ }^{1}$, Alison M McManus², Tai-Hing Lam
}

\begin{abstract}
Non-exercise physical activity (NEPA) is an important part of energy expenditure. This study aimed to investigate the prevalence of exercise and NEPA among adolescents. In the HKSOS project 2006-2007, the proportions of Hong Kong Chinese adolescents $(N=32,005)$ achieving 60-minute exercise and 60-minute NEPA per day were analyzed. Exercise was defined as structured and planned physical activities, and NEPA was defined as unstructured and unplanned physical activities including walking for transportation and climbing stairs. The prevalence of exercise was higher in boys than girls (after school: 63.8\% vs 39.6\%; holidays: $78.7 \%$ vs 60.0\%), but the prevalence of NEPA in boys was similar to that in girls (after school: $72.2 \%$ vs $68.0 \%$; holidays: $80.3 \%$ vs $79.4 \%$ ). In general, the prevalence of both exercise and NEPA decreased with age in boys and girls, but was more marked for exercise than NEPA. In conclusion, the prevalence of exercise was lower in adolescent girls than boys, and decreased more rapidly with age than NEPA. NEPA seems to be easier to accumulate than exercise among adolescents regardless of sex and age.
\end{abstract}

\section{Background}

Adolescent obesity is prevalent and physical inactivity is a major risk factor [1]. Current recommendation is for adolescents to perform at least 60 minutes of moderateto-vigorous physical activity (MVPA) daily [2]. However, time constraints [3] and lack of sports facilities [4] are known barriers for meeting this recommendation. Among UK secondary school students, MVPA took place mainly out of school rather than in school [5]. In Hong Kong, mainstream secondary schools have fairly uniform lesson schedules with physical education offered in two 40-minute lessons per week. Previous work in mainstream primary schools in Hong Kong has shown MVPA within the school day is negligible [6]. We therefore could assume that similar to the UK, after-school recreation activities would be the main contributor of the daily inter- and intra-individual variance in exercise levels in Hong Kong adolescents. Unlike exercise, non-exercise physical activities (NEPA) are mainly low intensity non-volitional activities such as walking, which are embedded into much of daily life abrogating the need for extra time or special facility [7].

\footnotetext{
* Correspondence: syho@hku.hk

'Department of Community Medicine and School of Public Health, The

University of Hong Kong 21 Sassoon Road, Pokfulam, Hong Kong

Full list of author information is available at the end of the article
}

Epidemiological studies have shown that low-intensity physical activity plays an important role in metabolic and cardiovascular health $[8,9]$. Indeed low-intensity exercise has been found to improve glucose profile [10] and is the most appropriate intensity for maximizing fat oxidation [11]. Evidence is also available to show that it is the low-intensity incidental activity, rather than the planned moderate- or vigorous-intensity activity, that distinguishes the lean from the obese [12]. Since little is known about NEPA among adolescents, we investigated the prevalence of exercise and NEPA among Chinese adolescents.

\section{Methods}

The Hong Kong Student Obesity Surveillance (HKSOS) project was conducted in 2006-2007 among 32,005 adolescents $(44.6 \%$ boys $)$ aged $13-18($ mean $=14.9)$ years from 42 schools, representing mainstream secondary schools in district, funding source, mixed/single sex education, teaching language, and religion. This study met the ethical standards suggested by Harriss and Atkinson [13], and ethics approval was obtained from the local Institutional Review Board.

The students reported the average duration they spent per day each on exercise and NEPA (i) after school and (ii) during holidays (non-school days), with 10 options 
including 30 minutes, 1 hour, 1.5 hour and other durations of up to 5 hours and above. School days and holidays were assessed separately to allow for differences in activity patterns. We did not measure activity durations within school hours to avoid counting time spent on compulsory physical education lessons. Exercise was defined as structured and planned physical activities, and sports such as jogging, swimming, water sports, ball games, hiking, and dancing, etc. NEPA was defined as movement necessary for normal living, including walking for transportation and climbing stairs.

Following the physical activity recommendation, "1 hour" was defined as the cutoff for exercise. With no standard recommendations available, the same cutoff was adopted for NEPA to facilitate its comparison with exercise. The prevalence of having exercise, NEPA, or either one after school and during holidays was examined with stratification by sex and age. Pearson's Chi-square test was used to examine sex differences in exercise and NEPA.

\section{Results}

Table 1 shows that the prevalence of exercise after school and during holidays was high in boys $(63.8 \%$ and

Table 1 Prevalence of having 60 minutes of exercise in school days and holidays

\begin{tabular}{|c|c|c|c|}
\hline & $\begin{array}{c}\text { Boys ( } \mathrm{n}=14,274) \\
\%\end{array}$ & $\begin{array}{c}\text { Girls ( } \mathrm{n}=17,731) \\
\%\end{array}$ & *P \\
\hline \multicolumn{4}{|l|}{ School days } \\
\hline \multicolumn{4}{|l|}{ Age group } \\
\hline 12 or below & 66.8 & 52.5 & $<0.001$ \\
\hline 13 & 66.4 & 44.9 & $<0.001$ \\
\hline 14 & 65.4 & 41.6 & $<0.001$ \\
\hline 15 & 64.2 & 38.4 & $<0.001$ \\
\hline 16 & 64.1 & 33.6 & $<0.001$ \\
\hline 17 & 59.5 & 28.1 & $<0.001$ \\
\hline 18 or above & 53.0 & 26.1 & $<0.001$ \\
\hline All & 63.8 & 39.6 & $<0.001$ \\
\hline P for trend & $<0.001$ & $<0.001$ & \\
\hline \multicolumn{4}{|l|}{ Holidays } \\
\hline \multicolumn{4}{|l|}{ Age group } \\
\hline 12 or below & 80.3 & 70.6 & $<0.001$ \\
\hline 13 & 79.4 & 65.1 & $<0.001$ \\
\hline 14 & 79.8 & 61.9 & $<0.001$ \\
\hline 15 & 79.0 & 58.7 & $<0.001$ \\
\hline 16 & 77.9 & 53.8 & $<0.001$ \\
\hline 17 & 76.6 & 49.9 & $<0.001$ \\
\hline 18 or above & 74.6 & 50.3 & $<0.001$ \\
\hline All & 78.7 & 60.0 & $<0.001$ \\
\hline$P$ for trend & $<0.001$ & $<0.001$ & \\
\hline
\end{tabular}

* P-value for the level of significance of sex differences determined by Pearson's Chi-square test.
$78.7 \%)$, but significantly lower in girls $(39.6 \%$ and $60.0 \%)$. Exercise decreased with age especially after school and among girls. At age of 18 years or above, only $53.0 \%$ boys and $26.1 \%$ girls exercised after school, while $74.6 \%$ boys and $50.3 \%$ girls exercised during holidays.

Table 2 shows that the prevalence of NEPA was high after school and during holidays both in boys $(72.2 \%$ and $80.3 \%)$ and in girls (68.0\% and $79.4 \%)$ Moreover, the prevalence of NEPA was relatively stable across age. At age 18 years or above, the prevalence of NEPA after school and during holidays remained high in boys (67.5\% and $78.4 \%$ ) and in girls (61.0\% and $74.9 \%)$. Furthermore, Table 3 shows that the prevalence of having 60 minutes of either exercise or NEPA is stable across age groups in boys (about 70\%) after school, and in both boys (about 80\%) and girls (about 80\%) during holidays.

\section{Discussion}

Sixty-four percent of the boys and $40 \%$ of the girls achieved the recommended 60 minutes of exercise daily after school (5 days) in Hong Kong. These are higher than those reported by the Youth Risk Behavior Surveillance

Table 2 Prevalence of having 60 minutes of non-exercise physical activity in school days and holidays

\begin{tabular}{|c|c|c|c|}
\hline & $\begin{array}{c}\text { Boys }(n=14,274) \\
\%\end{array}$ & $\begin{array}{c}\text { Girls }(n=17,731) \\
\%\end{array}$ & $* P$ \\
\hline \multicolumn{4}{|l|}{ School days } \\
\hline \multicolumn{4}{|l|}{ Age group } \\
\hline 12 or below & 73.1 & 72.3 & 0.53 \\
\hline 13 & 72.0 & 69.3 & 0.04 \\
\hline 14 & 74.5 & 69.8 & $<0.001$ \\
\hline 15 & 72.0 & 68.5 & 0.01 \\
\hline 16 & 72.1 & 66.6 & $<0.001$ \\
\hline 17 & 71.9 & 63.4 & $<0.001$ \\
\hline 18 or above & 67.5 & 61.0 & $<0.001$ \\
\hline All & 72.2 & 68.0 & $<0.001$ \\
\hline P for trend & 0.005 & $<0.001$ & \\
\hline \multicolumn{4}{|l|}{ Holidays } \\
\hline \multicolumn{4}{|l|}{ Age group } \\
\hline 12 or below & 80.5 & 82.7 & 0.047 \\
\hline 13 & 79.4 & 81.2 & 0.11 \\
\hline 14 & 80.7 & 79.1 & 0.16 \\
\hline 15 & 79.5 & 80.7 & 0.29 \\
\hline 16 & 81.8 & 77.1 & $<0.001$ \\
\hline 17 & 81.5 & 76.5 & 0.002 \\
\hline 18 or above & 78.4 & 74.9 & 0.03 \\
\hline All & 80.3 & 79.4 & 0.053 \\
\hline P for trend & 0.95 & $<0.001$ & \\
\hline
\end{tabular}

* P-value for the level of significance of sex differences determined by Pearson's Chi-square test. 
Table 3 Prevalence of having 60 minutes of either exercise or non-exercise physical activity in school days and holidays

\begin{tabular}{|c|c|c|c|}
\hline & $\begin{array}{c}\text { Boys }(n=14,274) \\
\%\end{array}$ & $\begin{array}{c}\text { Girls }(n=17,731) \\
\%\end{array}$ & ${ }^{* P}$ \\
\hline \multicolumn{4}{|l|}{ School days } \\
\hline \multicolumn{4}{|l|}{ Age group } \\
\hline 12 or below & 74.4 & 73.6 & 0.51 \\
\hline 13 & 74.7 & 71.0 & 0.003 \\
\hline 14 & 75.7 & 71.4 & $<0.001$ \\
\hline 15 & 76.6 & 71.6 & $<0.001$ \\
\hline 16 & 76.0 & 69.1 & $<0.001$ \\
\hline 17 & 76.4 & 65.9 & $<0.001$ \\
\hline 18 or above & 70.9 & 64.2 & $<0.001$ \\
\hline All & 75.1 & 70.3 & $<0.001$ \\
\hline$P$ for trend & 0.68 & $<0.001$ & \\
\hline \multicolumn{4}{|l|}{ Holidays } \\
\hline \multicolumn{4}{|l|}{ Age group } \\
\hline 12 or below & 81.5 & 81.7 & 0.87 \\
\hline 13 & 80.4 & 81.9 & 0.18 \\
\hline 14 & 81.1 & 80.2 & 0.40 \\
\hline 15 & 82.8 & 81.9 & 0.43 \\
\hline 16 & 82.5 & 78.5 & 0.001 \\
\hline 17 & 83.4 & 78.8 & 0.002 \\
\hline 18 or above & 82.1 & 78.4 & 0.015 \\
\hline All & 81.8 & 80.5 & 0.003 \\
\hline $\mathrm{P}$ for trend & 0.04 & $<0.001$ & \\
\hline
\end{tabular}

* P-value for the level of significance of sex differences determined by Pearson's Chi-square test.

2009 for students in the US, with $37 \%$ (45.6\% in boys and $27.7 \%$ in girls) achieving the recommended 60 minutes of exercise per day on 5 or more days [14]. The prevalence we report is similar to a recent study of $9-13$ year old Hong Kong primary school students, over $60 \%$ of whom achieved at least 60 minutes of MVPA per day [15]. These findings suggest that Hong Kong students spend more time exercising than their counterparts in the US, but since exercising is socially desirable, some over-reporting is also possible. Although the prevalence of exercise during holidays was higher, holidays were comparatively few throughout the year. That boys exercised more frequently than girls corresponds with previous findings from elsewhere [16-18]. Apart from time and sports facility constraints, adolescent girls may find exercise unappealing and this may make light-intensity NEPA easier to accumulate [19]. Consideration of body image in this age group is also important since some adolescents are reluctant to appear publicly in sportswear due to body dissatisfaction [20] or cultural concerns [21]. The declining trend of exercise with age we report is similar to that in Western adolescents [22,23], probably due to greater academic pressure and longer screen time [24] in senior grades.
In contrast, over two-thirds of girls and boys similarly achieved over 60 minutes of NEPA after school or during holidays. There are no existing data on NEPA in adolescents for comparison, but the prevalence of light-intensity physical activity was reported to be similar between adolescent boys and girls [25] or even higher in girls [26,27]. When both exercise and NEPA were considered, the prevalence rates of having either type of physical activity for 60 minutes were similar in boys and girls, both in school days and during holidays.

Hong Kong is highly urbanized with few natural environments designated for sports activities. The hot and humid weather in summer months may also discourage strenuous sports or exercise [28]. In addition, Hong Kong adolescents spend a great deal of time studying [29] and their recreational preferences are mostly sedentary digital entertainment such as computer use and digital games [4]. Therefore, it is of little surprise that some adolescents in Hong Kong fail to meet the current recommendation of 60 minutes of moderate-to-vigorous exercise daily, which may be an unrealistic goal for these youngsters. Nevertheless, Hong Kong is a highly walkable city [30] with shops and services in most residential areas and multiple connecting walk-ways which remove pedestrians from the dense traffic. NEPA, as a form of light physical activity, is easy to achieve and accumulate in daily life even among sedentary individuals [31,32]. Lowintensity activities such as walking may prevent heart diseases [33-35] and many other chronic diseases [36] in adults, and possibly also in adolescents. NEPA may be a good alternative to exercise for inactive adolescents, especially for girls, to increase their physical activity level and clearly has potential health benefits.

A limitation of our study was that simple questions were used to measure exercise and NEPA durations. However, the higher prevalence of activities observed in boys, younger students and during holidays as expected lent support to the validity of these measures. Simple questions also have an advantage in large-scale epidemiological studies such as the present study, but objective validation of this subjective measure of NEPA is still warranted. We acknowledge that both walking for transportation and stair climbing could be moderate to vigorous in intensity. However, walking for transportation is often of low speed (around $2 \mathrm{~km}$ /hour, unpublished data from our laboratory) and low intensity; stair climbing tends to be up a small number of stairs only and seldom chosen when an escalator or elevator are alternative options. Therefore, including these walking activities within the NEPA category was probably more appropriate. We have also assumed that NEPA and after-school exercise are the main contributors to the variance in total physical activity levels; however, this still needs to be confirmed in this population. 


\section{Conclusions}

The prevalence of exercise was lower in adolescent girls than boys, and decreased with age in both sexes. In contrast, NEPA remained high over time and was comparable between boys and girls. NEPA seems to be easier to accumulate than exercise among adolescents regardless of sex and age.

\section{Author details}

${ }^{1}$ Department of Community Medicine and School of Public Health, The University of Hong Kong 21 Sassoon Road, Pokfulam, Hong Kong. ${ }^{2}$ Institute of Human Performance, The University of Hong Kong 7 Sassoon Road, Pokfulam, Hong Kong.

\section{Authors' contributions}

KKM analyzed the data and wrote the first draft. SYH is principal investigator of the HKSOS project, interpreted the results and critically revised the manuscript. WSL and AMM revised the manuscript for important intellectual content. THL oversaw the HKSOS project and critically revised the manuscript. All authors read and approved the final manuscript.

\section{Competing interests}

The authors declare that they have no competing interests.

Received: 10 August 2010 Accepted: 20 January 2011

Published: 20 January 2011

\section{References}

1. Sinha A, Kling S: A review of adolescent obesity: prevalence, etiology, and treatment. Obes Surg 2009, 19(1):113-120.

2. U.S. Department of Health \& Human Services: 2008 Physical Activity Guidelines for Americans. Washington 2008.

3. Tappe MK, Duda JL, Ehrnwald PM: Perceived barriers to exercise among adolescents. J Sch Health 1989, 59(4):153-155.

4. Wong BY, Cerin E, Ho SY, Mak KK, Lo WS, Lam TH: Adolescents' physical activity: competition between perceived neighborhood sport facilities and home media resources. Int J Pediatr Obes 2010, 5(2):169-176.

5. Gidlow CJ, Cochrane T, Davey R, Smith H: In-school and out-of-school physical activity in primary and secondary school children. J Sports Sci 2008, 26(13):1411-1419.

6. McManus AM, Masters RS, Laukkanen RM, Yu CC, Sit CH, Ling FC: Using heart-rate feedback to increase physical activity in children. Prev Med 2008, 47(4):402-408.

7. Kotz CM, Levine JA: Role of nonexercise activity thermogenesis (NEAT) in obesity. Minn Med 2005, 88(9):54-57.

8. Healy GN, Dunstan DW, Salmon J, Cerin E, Shaw JE, Zimmet PZ, Owen N: Objectively measured light-intensity physical activity is independently associated with 2-h plasma glucose. Diabetes Care 2007, 30(6):1384-1389

9. Matthews CE, Jurj AL, Shu XO, Li HL, Yang G, Li Q, Gao YT, Zheng W: Influence of exercise, walking, cycling, and overall nonexercise physical activity on mortality in Chinese women. Am J Epidemiol 2007, 165(12):1343-1350

10. Sothern MS, Loftin M, Suskind RM, Udall JN, Blecker U: The health benefits of physical activity in children and adolescents: implications for chronic disease prevention. Eur J Pediatr 1999, 158(4):271-274.

11. Zunquin $G$, Theunynck D, Sesboue B, Arhan P, Bougle D: Comparison of fat oxidation during exercise in lean and obese pubertal boys: clinical implications. Br J Sports Med 2009, 43(11):869-870.

12. Levine JA, Eberhardt NL, Jensen MD: Role of nonexercise activity thermogenesis in resistance to fat gain in humans. Science 1999, 283(5399):212-214

13. Harriss DJ, Atkinson G: International Journal of Sports Medicine - ethical standards in sport and exercise science research. Int J Sports Med 2009, 30(10):701-702.

14. Eaton DK, Kann L, Kinchen S, Shanklin S, Ross J, Hawkins J, Harris WA, Lowry R, McManus T, Chyen D, Lim C, Whittle L, Brener ND, Wechsler H:
Youth risk behavior surveillance - United States, 2009. MMWR Surveill Summ 2010, 59(5):1-142.

15. Lam JW, Sit CH, Cerin E: Physical activity and sedentary behaviours in Hong Kong primary school children: Prevalence and gender differences. Prev Med 2010, 51(1):96-97.

16. Riddoch CJ, Bo Andersen L, Wedderkopp N, Harro M, Klasson-Heggebo L, Sardinha LB, Cooper AR, Ekelund U: Physical activity levels and patterns of 9- and 15-yr-old European children. Med Sci Sports Exerc 2004, 36(1):86-92.

17. Klasson-Heggebo L, Anderssen SA: Gender and age differences in relation to the recommendations of physical activity among Norwegian children and youth. Scand J Med Sci Sports 2003, 13(5):293-298.

18. Santos P, Guerra S, Ribeiro JC, Duarte JA, Mota J: Age and gender-related physical activity. A descriptive study in children using accelerometry. $J$ Sports Med Phys Fitness 2003, 43(1):85-89.

19. Pate RR, Stevens J, Pratt C, Sallis JF, Schmitz KH, Webber LS, Welk G, Young DR: Objectively measured physical activity in sixth-grade girls. Arch Pediatr Adolesc Med 2006, 160(12):1262-1268.

20. Ball $K$, Crawford D, Owen N: Too fat to exercise? Obesity as a barrier to physical activity. Aust N Z J Public Health 2000, 24(3):331-333.

21. Eyler AA, Matson-Koffman D, Vest JR, Evenson KR, Sanderson B, Thompson JL, Wilbur J, Wilcox S, Young DR: Environmental, policy, and cultural factors related to physical activity in a diverse sample of women: The Women's Cardiovascular Health Network Project-summary and discussion. Women Health 2002, 36(2):123-134.

22. Sherar LB, Esliger DW, Baxter-Jones AD, Tremblay MS: Age and gender differences in youth physical activity: does physical maturity matter? Med Sci Sports Exerc 2007, 39(5):830-835.

23. Trost SG, Pate RR, Sallis JF, Freedson PS, Taylor WC, Dowda M, Sirard J: Age and gender differences in objectively measured physical activity in youth. Med Sci Sports Exerc 2002, 34(2):350-355.

24. Sharif I, Sargent JD: Association between television, movie, and video game exposure and school performance. Pediatrics 2006, 118(4): e1061-1070.

25. Gavarry O, Giacomoni M, Bernard T, Seymat M, Falgairette G: Habitual physical activity in children and adolescents during school and free days. Med Sci Sports Exerc 2003, 35(3):525-531.

26. Trost SG, Rosenkranz RR, Dzewaltowski D: Physical activity levels among children attending after-school programs. Med Sci Sports Exerc 2008, 40(4):622-629.

27. Dunton GF, Whalen CK, Jamner LD, Henker B, Floro JN: Using ecologic momentary assessment to measure physical activity during adolescence. Am J Prev Med 2005, 29(4):281-287.

28. Eves FF, Masters RS, McManus A, Leung M, Wong P, White MJ: Contextual barriers to lifestyle physical activity interventions in Hong Kong. Med Sci Sports Exerc 2008, 40(5):965-971.

29. Mak KK, Day JR: Secular trends of sports participation, sedentary activity and physical self-perceptions in Hong Kong adolescents, 1995-2000. Acta Paediatr 2010, 99(11):1731-1734.

30. Cerin E, Saelens BE, Sallis JF, Frank LD: Neighborhood Environment Walkability Scale: validity and development of a short form. Med Sci Sports Exerc 2006, 38(9):1682-1691.

31. Siegel PZ, Brackbill RM, Heath GW: The epidemiology of walking for exercise: implications for promoting activity among sedentary groups. Am J Public Health 1995, 85(5):706-710.

32. Besser LM, Dannenberg AL: Walking to public transit: steps to help meet physical activity recommendations. Am J Prev Med 2005, 29(4):273-280.

33. Manson JE, Greenland P, LaCroix AZ, Stefanick ML, Mouton CP, Oberman A, Perri MG, Sheps DS, Pettinger MB, Siscovick DS: Walking compared with vigorous exercise for the prevention of cardiovascular events in women. N Engl J Med 2002, 347(10):716-725

34. Gaenzer H, Sturm W, Neumayr G: Effects of walking on coronary heart disease in elderly men. Circulation 2000, 102(2):E16.

35. Hakim AA, Curb JD, Petrovitch $H$, Rodriguez BL, Yano K, Ross GW, White LR, Abbott RD: Effects of walking on coronary heart disease in elderly men: the Honolulu Heart Program. Circulation 1999, 100(1):9-13.

36. Lee IM, Buchner DM: The importance of walking to public health. Med SCi Sports Exerc 2008, 40(7 Suppl):S512-518.

doi:10.1186/1479-5868-8-3

Cite this article as: Mak et al:: Prevalence of exercise and non-exercise physical activity in Chinese adolescents. International Journal of Behavioral Nutrition and Physical Activity 2011 8:3. 